\title{
Rattlesnake Crotalus molossus nigrescens venom induces oxidative stress on human erythrocytes
}

David Meléndez-Martínez', Juan Manuel Muñoz ', Guillermo Barraza-Garza', Martha Sandra Cruz-Peréz², Ana Gatica-Colima ${ }^{1}$, Emilio Alvarez-Parrilla ${ }^{1}$ and Luis Fernando Plenge-Tellechea ${ }^{1 *}$

\begin{abstract}
Background: Globally, snake envenomation is a well-known cause of death and morbidity. In many cases of snakebite, myonecrosis, dermonecrosis, hemorrhage and neurotoxicity are present. Some of these symptoms may be provoked by the envenomation itself, but others are secondary effects of the produced oxidative stress that enhances the damage produced by the venom toxins. The only oxidative stress effect known in blood is the change in oxidation number of Fe (from ferrous to ferric) in hemoglobin, generating methemoglobin but not in other macromolecules. Currently, the effects of the overproduction of methemoglobin derived from snake venom are not extensively recorded. Therefore, the present study aims to describe the oxidative stress induced by Crotalus molossus nigrescens venom using erythrocytes.
\end{abstract}

Methods: Human erythrocytes were washed and incubated with different Crotalus molossus nigrescens venom concentrations $(0-640 \mu \mathrm{g} / \mathrm{mL})$. After $24 \mathrm{~h}$, the hemolytic activity was measured followed by attenuated total reflectance-Fourier transform infrared spectroscopy, non-denaturing PAGE, conjugated diene and thiobarbituric acid reactive substances determination.

Results: Low concentrations of venom $(<10 \mu \mathrm{g} / \mathrm{mL})$ generates oxyhemoglobin release by hemolysis, whereas higher concentrations produced a hemoglobin shift of valence, producing methemoglobin $(>40 \mu \mathrm{g} / \mathrm{mL})$. This substance is not degraded by proteases present in the venom. By infrared spectroscopy, starting in $80 \mu \mathrm{g} / \mathrm{mL}$, we observed changes in bands that are associated with protein damage $\left(1660\right.$ and $\left.1540 \mathrm{~cm}^{-1}\right)$ and lipid peroxidation (2960, 2920 and $1740 \mathrm{~cm}^{-1}$ ). Lipid peroxidation was confirmed by conjugated diene and thiobarbituric acid reactive substance determination, in which differences were observed between the control and erythrocytes treated with venom.

Conclusions: Crotalus molossus nigrescens venom provokes hemolysis and oxidative stress, which induces methemoglobin formation, loss of protein structure and lipid peroxidation.

Keywords: Attenuated total reflectance-Fourier transform infrared spectroscopy, Crotalus molossus nigrescens, Venom, Snake venom, Methemoglobin, Oxidative stress, Oxyhemoglobin

\footnotetext{
* Correspondence: fplenge@uacj.mx

'Departamento de Ciencias Químico Biológicas, Instituto de Ciencias

Biomédicas, Universidad Autónoma de Ciudad Juárez, Anillo Envolvente del

PRONAF y Estocolmo s/n, C. P. 32310. A. P. 1595-D Ciudad Juárez, Chihuahua,

Mexico

Full list of author information is available at the end of the article
} 


\section{Background}

Snakebites cause considerable death and high morbidity worldwide and pose an important threat to public health, especially those provoked by Crotalus snakes [1-4]. Rattlesnake envenomation alters the homeostasis of victims, generating coagulation alterations and hemorrhage that may provoke death. Rattlesnake envenomation may cause myonecrosis, dermonecrosis, neurotixicity, different types of damage to the vascular extracellular matrix, and edema [5]. These effects are generated by some toxins such as phospholipases $\mathrm{A}_{2} \quad\left(\mathrm{PLA}_{2}\right)$, low molecular mass myotoxins, L-amino acid oxidases (LAAO) and proteases including metalloproteinases (SVMPs) and serineproteinases (SVSPs) [6-8]. In addition, reactive oxygen species (ROS) are produced as a side effect of the catalytic activity of some toxins, enhancing the damage produced by the venom and causing systemic oxidative stress [9].

The different scenarios on the oxidative stress indicate that are unrecognized and underestimated forms of affliction provoked by snakes. SVMPs, major components in most Crotalid venoms, have a relevant role in venominduced local damage. The lethality of this venom is due to the high activity of $\mathrm{PLA}_{2}$ that hydrolyzes phospholipids and releases arachidonic acid, which, in turn, generates toxic reactive oxygen species (ROS) $[10,11]$. This reaction results in lipid peroxidation and leads to cellular damage [12].

Cells have antioxidant defenses against toxic ROS such as the enzymes superoxide dismutase (SOD) and catalase (CAT) - that work in tandem to neutralize superoxide radicals [13-15]. SOD catalyzes the loss of superoxide radicals into oxygen or hydrogen peroxide $\left(\mathrm{H}_{2} \mathrm{O}_{2}\right)$; this is itself detrimental and must be detoxified into other non-toxic substances. By another way, CAT helps in the decomposition of $\mathrm{H}_{2} \mathrm{O}_{2}$ into water and oxygen [16]. All these responses are part of the reactions triggered by $C$. $m$. nigrescens venom (CMNv), which produce significant oxidative stress in different stages. Thus, an important role of lipid peroxidation in cytotoxicity of $C . m$. nigrescens envenomation is suggested. Based on these relevant findings of oxidative stress produced by snakebite, the present study aims to describe the oxidative stress induced by CMNv using a model of isolated erythrocytes.

\section{Methods}

\section{Venom}

Venom samples were obtained from $C . m$. nigrescens specimens maintained at the Universidad Autónoma de Queretaro herpetarium. Venom extraction was performed manually as described by Meléndez-Martínez et al. [17]. $\mathrm{CMNv}$ was pooled, lyophilized and stored at $-20{ }^{\circ} \mathrm{C}$ until use. Protein concentration in venom was measured by
Lowry protein assay [18], using bovine serum albumin as standard.

\section{Hemolytic activity}

Hemolytic activity was determined using Das et al. [19] protocol with some modifications. Blood was collected from at least three healthy donors for each experiment. Inclusion criteria were: $\mathrm{O}+$ donors that had not taken any medication $48 \mathrm{~h}$ before the test. Blood samples were collected in BD Vacutainer ${ }^{\oplus}$ buffered sodium citrate tubes and erythrocytes were isolated and washed thrice by centrifugation at $1,100 \mathrm{~g}$ and re-suspended in $0.9 \%$ saline solution to a final concentration of $20 \%$. Then, $37.5 \mu \mathrm{L}$ of erythrocyte suspension was incubated during $24 \mathrm{~h}$ at $37{ }^{\circ} \mathrm{C}$ with different $\mathrm{CMNv}$ concentrations (0$640 \mu \mathrm{g} / \mathrm{mL}$ ) in a $500 \mu \mathrm{L}$ final volume. Next, the samples were centrifuged at $6,400 \mathrm{~g}$ for $10 \mathrm{~min}$ and supernatant was measured at $540 \mathrm{~nm}$ for oxyhemoglobin (Oxy- $\mathrm{Hb})$ and $630 \mathrm{~nm}$ for methemoglobin (Met-Hb) in a Helios Omega UV-vis spectrophotometer (Thermo Scientific, USA). As 100\% Oxy-Hb and Met-Hb controls distilled $\mathrm{H}_{2} \mathrm{O}$ and $\mathrm{H}_{2} \mathrm{O}_{2} 5 \%$ (v/v) were used, respectively.

\section{Polyacrylamide gel electrophoresis}

These experiments were carried out under nondenaturing and denaturing polyacrylamide gel electrophoresis (PAGE) using a $15 \%$ acrylamide gel modified from Sambrook and Russell [20] to observe the degradation of the hemoglobin $(\mathrm{Hb})$. Treated erythrocytes were centrifuged as described above and $50 \mu \mathrm{g}$ of soluble $\mathrm{Hb}$ was collected to use in the gels and stained $0.1 \%$ Coomassie blue R-250 staining. The samples used in denaturing PAGE were sand boiled by $5 \mathrm{~min}$ before the electrophoresis.

\section{Attenuated total reflectance-Fourier transform infrared spectroscopy}

Erythrocytes were treated as described in hemolysis assay. The CMNv treated erythrocytes were analyzed in attenuated total reflectance-Fourier transform infrared (ATR-FTIR) in a Bruker Alpha FTIR Spectrometer (Bruker Optics, USA), according to the method described in Barraza-Garza et al. [21]. Briefly, $4 \mu \mathrm{L}$ of treated erythrocytes were placed at the spectrometer and were allowed to dry for $10 \mathrm{~min}$. Spectra were recorded in a range from 4000 to $900 \mathrm{~cm}^{-1}$ with a maximum resolution of $6 \mathrm{~cm}^{-1}$, and 200 scans per spectrum were collected. Three spectra were recorded for each treatment.

\section{Infrared spectra analysis}

Infrared (IR) spectra were analyzed using Unscrambler ${ }^{\bullet}$ $\mathrm{X}$ software (CAMO Software, Norway). Raw spectra were preprocessed using first vector normalization and then a second derivative using Savitsky-Golay of second 
polynomial order with 21 smoothing points. The second derivative spectra obtained was analyzed in order to observe differences in intensity and position of the signals. The analysis was made in three main zones across the spectra that are related to chemical bonds liable to damage via oxidative stress [21]: $\sim 1550-1660 \mathrm{~cm}^{-1}$ region for amide I and II, $\sim 1740-1780 \mathrm{~cm}^{-1}$ region for aldehyde bond and $\sim 2920-2960 \mathrm{~cm}^{-1}$ region for primary and secondary carbon bonds in lipid skeletons.

\section{Conjugated dienes determination}

Conjugated dienes (CD) were determined according to Barraza-Garza et al. [21] with slight modifications. After treatment, the erythrocytes were resuspended in $900 \mu \mathrm{L}$ of methanol:chloroform (1:2) solution and vortexed for $2 \mathrm{~min}$. The mixture was centrifuged for $10 \mathrm{~min}$ at $4650 \mathrm{~g}$ and the chloroform phase was collected and dried with a nitrogen flux. Then, lipids were dissolved in $200 \mu \mathrm{L}$ of cyclohexane, mixed by vortex for $30 \mathrm{~s}$ and immediately measured at $233 \mathrm{~nm}$ in a Helios Omega UV-vis spectrophotometer (Thermo Scientific, USA) using cyclohexane as blank. Absorbance was converted to conjugated dienes concentration using an extinction coefficient of $27000 \mathrm{M}$ ${ }^{-1} \mathrm{~cm}^{-1}$ and the results were expressed as concentration $(\mu \mathrm{M})$ of conjugated dienes per sample.

\section{Thiobarbituric acid reactive substances assay}

Thiobarbituric acid reactive substances assay (TBARS) was performed according to Barraza-Garza et al. [21] with slight modifications. After treatment, $100 \mu \mathrm{L}$ of venom-treated erythrocytes were mixed with $400 \mu \mathrm{L}$ of thiobarbituric acid reagent $(20 \%$ trichloroacetic acid; $0.5 \%$ thiobarbituric acid and $2.5 \mathrm{~N} \mathrm{HCl}$ ) and the mixture was heated for $1 \mathrm{~h}$ at $75{ }^{\circ} \mathrm{C}$. After cooling, the solution was centrifuged at $380 \mathrm{~g}$ for $10 \mathrm{~min}$ and the absorbance of supernatant was measured at $532 \mathrm{~nm}$ in a Helios Omega UV-vis spectrophotometer (Thermo Scientific, USA) using the reaction mixture as a blank. Results were expressed as concentration $(\mu \mathrm{M})$ of malondialdehyde (MDA) per sample. A calibration curve was prepared with tetramethoxypropane (which is equivalent to the same concentrations of MDA) with concentrations ranging from 1.25 to $20 \mu \mathrm{M}$.

\section{Statistical analysis}

Results obtained with CD and TBARS were analyzed by a one-way analysis of variance (ANOVA). When ANOVA showed a significant difference, Tukey's post hoc test was applied. Multivariate analysis was made by PCA as described in the previous subsection, using Unscrambler $^{\ominus} \mathrm{X}$ software (CAMO Software, Norway).

\section{Results and discussion}

\section{Hemolytic activity}

In this assays we found that $\mathrm{CMNv}$ produces hemolysis observed as an Oxy-Hb release from the lysed erythrocyte (Fig. 1), the median hemolytic concentration was $1.00 \pm$ $0.07 \mu \mathrm{g} / \mathrm{mL}$ and showed a full hemolysis with $7.5 \mu \mathrm{g} / \mathrm{mL}$ of venom. At higher CMNv concentrations, > $40 \mu \mathrm{g} / \mathrm{mL}$, the Oxy-Hb concentration decreased and Met- $\mathrm{Hb}$ increased in a concentration-dependent manner having its higher concentration $(\approx 90 \%)$ at $160 \mu \mathrm{g} / \mathrm{mL}$ of venom.

Hemolysis could be produced as consequence of PLA phospholipid degradation and L-amino acid oxidase catalysis $[22,23]$. Due to Oxy-Hb release, the ferrous $\left(\mathrm{Fe}^{2+}\right)$ heme was converted to ferric $\left(\mathrm{Fe}^{3+}\right)$ heme resulting in Met- $\mathrm{Hb}$. This valence shift in $\mathrm{Hb}$ could be generated by oxidative stress induced by $\mathrm{H}_{2} \mathrm{O}_{2}$ produced by the LAAO catalysis [24, 25]. Then, $\mathrm{Hb}$ damage could be magnified by the Met-Hb formation itself, acting as a prooxidant molecule accelerating de process of Met$\mathrm{Hb}$ formation [26].

\section{Hemoglobin degradation}

The $\mathrm{Hb}$ exposed to the CMNv not only showed a valence shift, from $\mathrm{Oxy}-\mathrm{Hb}$ to Met- $\mathrm{Hb}$, but also a slight degradation of Met-Hb. The higher venom concentrations $(160,320$ and $640 \mu \mathrm{g} / \mathrm{mL})$ produced the $\mathrm{Hb}$ partial degradation (Fig. 2). Apparently, the proteases contained in the venom, SVMPs and SVSPs, had lesser affinity to $\mathrm{Hb}$ than other substrates as fibrinogen [27]. Moreover, basement membrane components including perlecan and nidogen are hydrolyzed within minutes, destabilizing the basement membrane and leading to hemorrhage $[28,29]$.

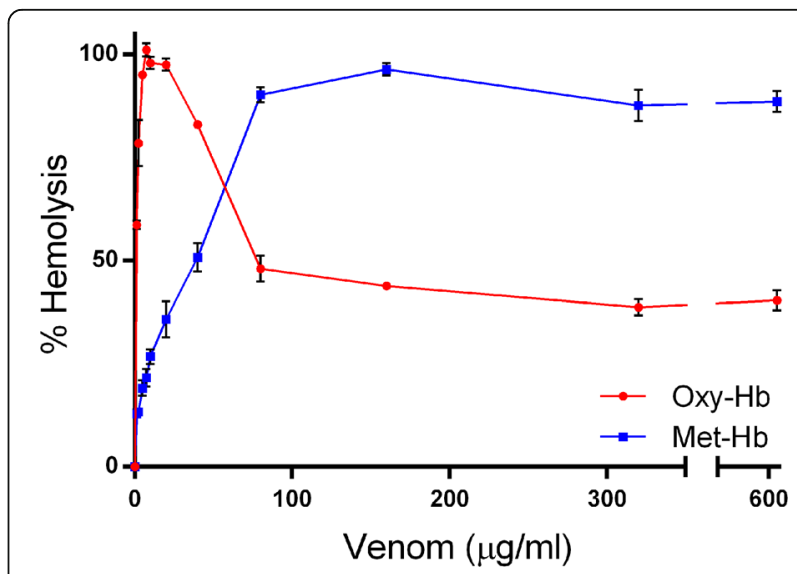

Fig. 1 Hemolytic effect of CMNv. Erythrocytes were treated with different concentrations of CMNv (0-640 $\mu \mathrm{g} / \mathrm{mL})$ for $24 \mathrm{~h}$. Oxy-Hb is represented by a red line and Met-Hb by a blue line. Data are represented as the mean of three independent experiments with its respective standard error 


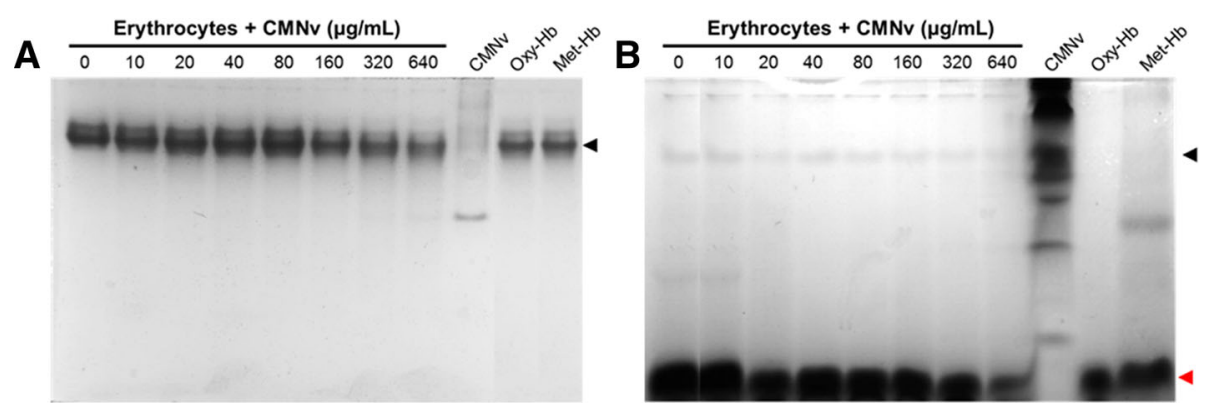

Fig. 2 PAGE of hemoglobin under (a) non-denaturing and (b) denaturing conditions - erythrocytes incubated with CMNv. Erythrocytes treated with different concentrations of CMNv for $24 \mathrm{~h}$ were centrifuged and soluble hemoglobin was used in this experiment. Lanes 1-8 show the erythrocytes treated with different venom concentrations, lane 9 shows $50 \mu \mathrm{g}$ of CMNv, lanes 10 and 11 show Oxy-Hb and Met-Hb controls, respectively. The hemoglobin $(64 \mathrm{kDa})$ is marked with a black arrow, a-globin and $\beta$-globin $(16 \mathrm{kDa})$ are marked with a red arrow head

\section{Oxidative stress evaluation by attenuated total} reflectance-Fourier transform infrared spectroscopy

Infrared spectroscopy allowed us to observe differences of the different biomolecules on erythrocytes due to oxidative stress by $\mathrm{CMNv}$ concentration increase. ATRFTIR analysis was carried out at the regions associated to lipid (2960, 2920 and $1740 \mathrm{~cm}^{-1}$ ) and protein oxidation (1660 and $1540 \mathrm{~cm}^{-1}$ ) bands to determine the oxidation in proteins. No differences were observed between control samples and those treated with a low venom concentration $(10-40 \mu \mathrm{g} / \mathrm{mL})$.

Changes observed in the region from 2920 to $2960 \mathrm{~cm}^{-1}$ are related to primary and secondary carbons in the lipid skeletons, respectively (Fig. 3a). The $80 \mu \mathrm{g} / \mathrm{mL}$ treatment showed the same IR profile as control, were the primary carbon band $\left(2920 \mathrm{~cm}^{-1}\right)$ had a higher intensity than the secondary carbon band $\left(2920 \mathrm{~cm}^{-1}\right)$, meaning that the lipid structure is not modified. At higher venom concentrations (320 and $640 \mu \mathrm{g} / \mathrm{mL}$ ) the proportion between primary and secondary carbons switches, showing higher intensity in the secondary carbon band; this shift may be related to the loss of integrity in the lipid structure. Benseny-Cases et al. [30] reported similar results when membrane lipids were attacked by oxidative radicals. They observed changes in the proportion of primary and secondary carbons in their skeletal lipids. In Fig. $3 b$, it can be seen that the peak intensity at $1740 \mathrm{~cm}^{-1}$ (associated to aldehyde compounds) increased as the venom concentration increased. Aldehyde compounds are secondary products of lipid oxidation, meaning that the venom may act as oxidative stress generator [21].

Changes in both amide I and II can be seen at venom concentrations higher than $80 \mu \mathrm{g} / \mathrm{mL}$. In Fig. $3 \mathrm{c}$ it is possible to observe a loss of symmetry of the peak and a displacement to higher wave number, and a decrease of intensity of both bands as the concentration of venom increases. This decrease in the intensity of the bands can be associated with changes in the secondary and tertiary structure from proteins, mainly $\mathrm{Hb}$, related to the loss of integrity of proteins caused by the oxidative stress [31].

\section{Spectrophotometric measures of lipid peroxidation by conjugated dienes and thiobarbituric acid reactive substances assay}

In the IR spectra analysis we saw a clear variation in the lipid composition of the samples, as we had mainly two types of lipid damage by the venom, namely:

- a change in the proportion of primary and secondary carbons of the lipid skeleton related to structure loss in lipids by lipid peroxidation;

- an intensity increase of the aldehyde band related to the production of secondary products of the lipid peroxidation.

In order to confirm the oxidation observed by FTIR, two spectrophotometric assays (TBARS and CD) were carried out. In Fig. 4a, it is possible to observe that the amount of $C D$ augmented steadily as the concentration of venom increased. Considering that $\mathrm{CD}$ is a primary product of lipid peroxidation, it is clear that $\mathrm{CMNv}$ lipid peroxidation products are generated by the oxidative stress provoked by the presence of the venom in a dose-dependent manner. In addition, we observed a low lipid peroxidation in $\mathrm{Oxy}-\mathrm{Hb}$ control in comparison to Met-Hb control, demonstrating that the Met-Hb can act as a prooxidant molecule. Based on the present results, the lipid peroxidation effects seen in the IR analysis are corroborated.

TBARS assay validated the effects observed in the ATR-FTIR assay for aldehyde band (Fig. 4b) as well as for CD. Through TBARS assay, it was possible to observe an increase of MDA as the concentration of venom augmented. However, this increase was only significant for the highest venom concentration. 


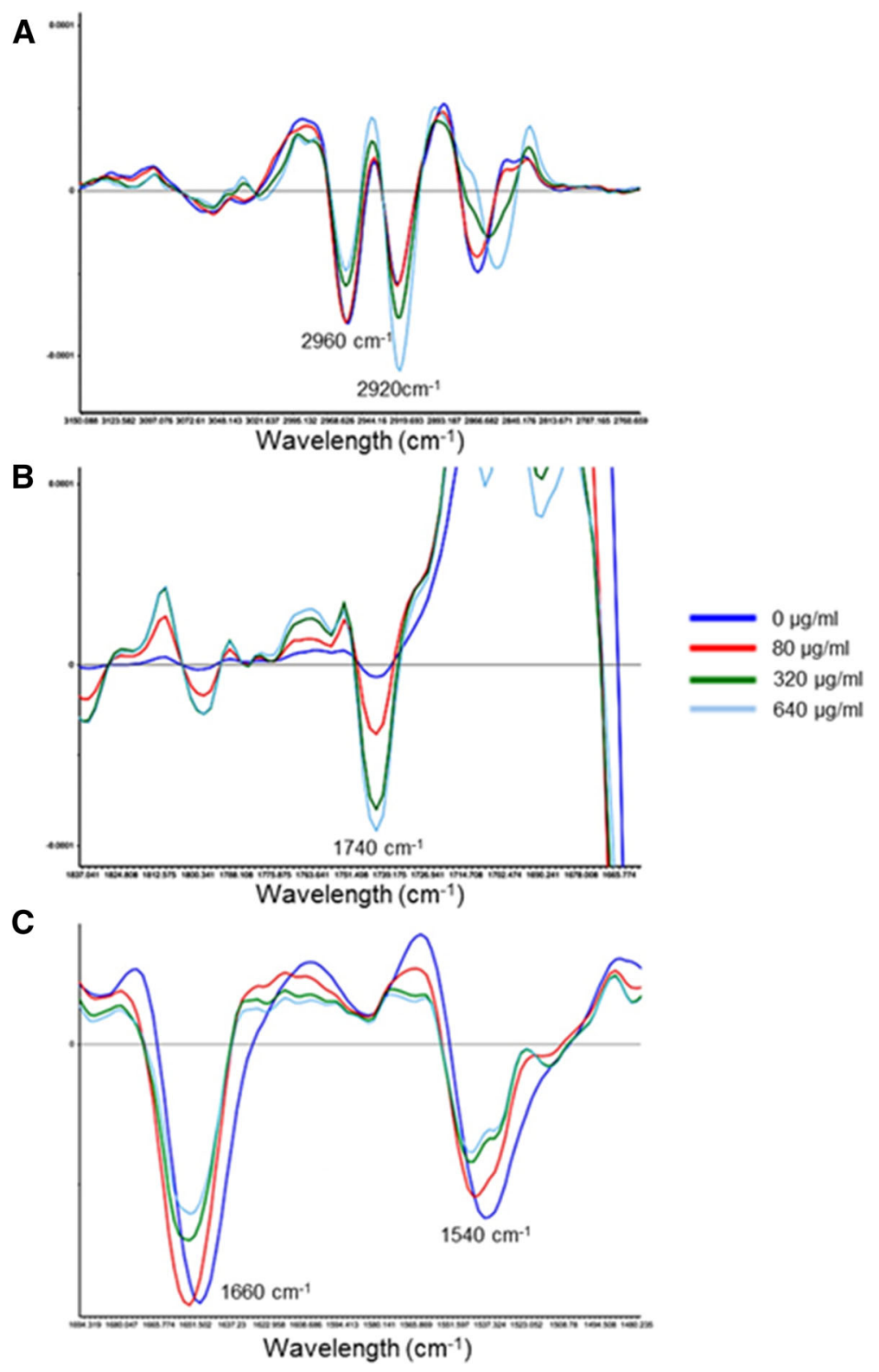

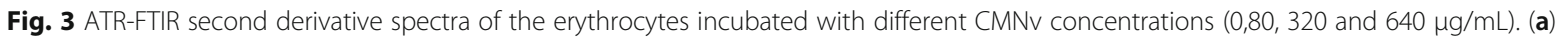
Second derivative of skeletal carbons of lipids, primary carbon $\left(2960 \mathrm{~cm}^{-1}\right)$ and secondary carbon $\left(2920 \mathrm{~cm}^{-1}\right)$ bands. b Second derivative of aldehyde bond band $\left(1740 \mathrm{~cm}^{-1}\right)$ related to secondary products of lipid peroxidation. $\mathbf{c}$ Second derivative of the amide bonds region, amide I $\left(1660 \mathrm{~cm}^{-1}\right)$ and amide $\|\left(1540 \mathrm{~cm}^{-1}\right)$ that are the main bands related to protein structure

Considering that TBARS represent the formation of secondary products of lipid peroxidation, this results may suggest that at the time and concentration studied, the venom produced mainly primary products of lipid oxidation. Interestingly, both $\mathrm{Oxy}-\mathrm{Hb}$ and Met$\mathrm{Hb}$ treatments had a lower concentration of MDA than that seen in the control treatment $(0 \mu \mathrm{g} / \mathrm{mL})$, suggesting that the catalytic activity of the venom is involved in the production of aldehyde compounds and not as an oxidative effect of Met-Hb.
This increment of MDA could be produced due the arachidonic acid release after $\mathrm{PLA}_{2}$ catalysis [11]. Moreover, the newly produced arachidonic acid could be oxidized by $\mathrm{H}_{2} \mathrm{O}_{2}$ produced by the LAAO catalysis [25]. Al Asmari et al. [32] reported an increment of MDA levels in the liver, kidney, heart, and brain of mice treated with Echis pyramidum venom. Similarly to our results, they reported a MDA increase after $24 \mathrm{~h}$ of incubation, suggesting that the oxidative stress produced by the $\mathrm{CMNv}$ in the erythrocytes can 

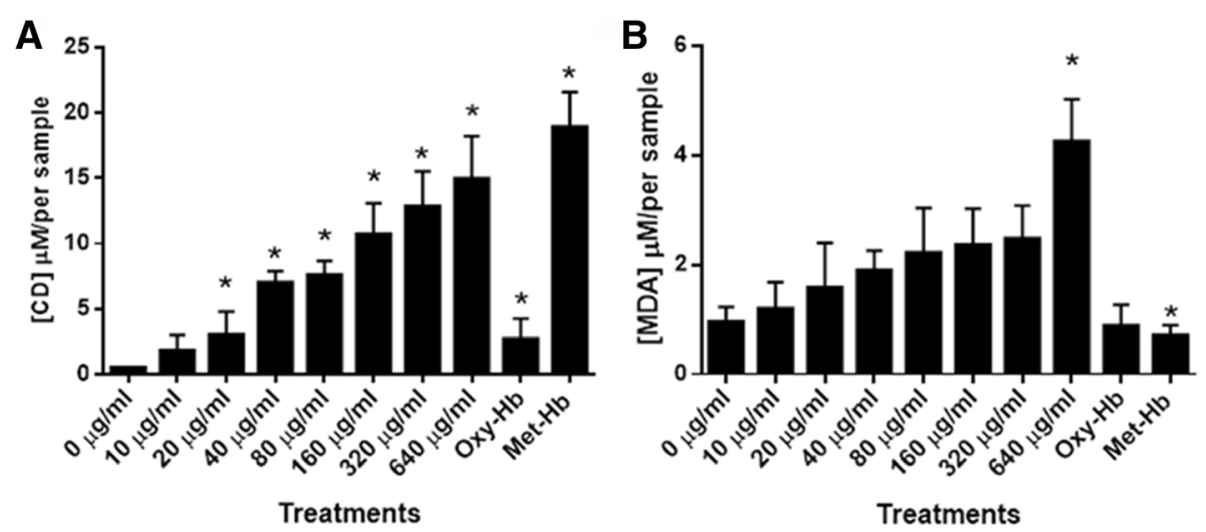

Fig. 4 Lipid peroxidation measurement by (a) CD and (b) TBARS assays of the erythrocytes incubated with Crotalus molossus nigrescens venom. Data are represented as the mean of various independent experiments with its respective standard error, statistical significance difference $(p<$ 0.05) respect to the control $(0 \mu \mathrm{g} / \mathrm{mL})$ is represented with an asterisk $\left(^{*}\right)$

lead to a systemic lipid peroxidation affecting other tissues.

\section{Conclusions}

In conclusion, through ATR-FTIR, CD, and TBARS we demonstrate that the venom of Crotalus molossus nigrescens is an oxidative stress inductor generating Met- $\mathrm{Hb}$, loss of protein structure and lipid peroxidation in erythrocytes, which can be related to some of the symptoms observed in the envenomation.

\section{Abbreviations \\ ANOVA: One-way analysis of variance; ATR-FTIR: Attenuated total reflectance- Fourier transform infrared; CAT: Catalase; CD: Conjugated dienes; \\ CMNv: Crotalus molossus nigrescens venom; $\mathrm{H}_{2} \mathrm{O}_{2}$ : Hydrogen peroxide; Hb: Hemoglobin; IR: Infrared; LAAO: L-amino acid oxidases; \\ MDA: Malondialdehyde; Met-Hb: Methemoglobin; Oxy-Hb: Oxyhemoglobin; PAGE: Polyacrylamide gel electrophopresis; PLA 2 : Phospholipase $A_{2 i}$ ROS: Reactive oxygen species; SOD: Superoxide dismutase; SVMPs: Snake Venom Metalloproteinases; SVSPs: Snake Venom Serineproteinases; TBARS: Thiobarbituric acid reactive substances assay}

\section{Acknowledgments}

Special acknowledgements to Dr. Simón Yobanny Reyes-López from Laboratorio de Materiales Híbridos Nanoestructurados from Universidad Autónoma de Ciudad Juárez for allowing us to use the ATR-FTIR spectrometer.

\section{Funding}

This project was supported by Programa Integral de Fortalecimiento Institucional, SEP (PIFI) for Academic Groups, Universidad Autónoma de Ciudad Juárez.

\section{Availability of data and materials}

Not applicable

\section{Authors' contributions}

DMM and GBG performed the experiments; MSCP contributed with the C. $m$. nigrescens venom used in this research; DMM, GBG, JMM, AGC, EAP and LFPT analyzed the data and wrote the paper. All the authors read and approved the final manuscript.

\section{Competing interests}

The authors declare that they have no competing interests.

\section{Ethics approval and consent to participate}

The C. $m$. nigrescens specimens used were maintained in captivity under permit of the Direccion General de Vida Silvestre of Secretaria de Medio Amiente y Recursos Naturales de México (INE/CITES/DGVS-CR-IN-0619-QRO-

00) at the Universidad Autónoma de Queretaro.

\section{Publisher's Note}

Springer Nature remains neutral with regard to jurisdictional claims in published maps and institutional affiliations.

\section{Author details}

${ }^{1}$ Departamento de Ciencias Químico Biológicas, Instituto de Ciencias Biomédicas, Universidad Autónoma de Ciudad Juárez, Anillo Envolvente del PRONAF y Estocolmo s/n, C. P. 32310. A. P. 1595-D Ciudad Juárez, Chihuahua, Mexico. ${ }^{2}$ Herpetario de la Universidad Autónoma de Querétaro, Facultad de Ciencias Naturales, Universidad Autónoma de Querétaro, Juriquilla,

Querétaro, Mexico.

Received: 5 November 2016 Accepted: 12 April 2017

Published online: 21 April 2017

\section{References}

1. Massougbodji M, Chobli M, Assouto P, Lokossou T, Sanoussi H, Sossou A. Geoclimatology and severity of snake bite envenomations in Benin. Bull Soc Pathol Exot. 2002:95(3):175-7.

2. Gutiérrez JM. Current challenges for confronting the public health problem of snakebite envenoming in Central America. J Venom Anim Toxins incl Trop Dis. 2014;20:7.

3. Habib GA. Public health aspects of snakebite care in West Africa: perspectives from Nigeria. J Venom Anim Toxins incl Trop Dis. 2013;19:27.

4. Chippaux JP. Epidemiology of envenomations by terrestrial venomous animals in Brazil based on case reporting: from obvious facts to contingencies. J Venom Anim Toxins incl Trop Dis. 2015;21:13.

5. Gutierrez JM, Lomonte B, Leon G, Rucavado A, Chaves F, Angulo Y. Trends in snakebite envenomation therapy: scientific, technological and public health considerations. Curr Pharm Des. 2007:13:2935-50.

6. Calvete JJ, Fasoli E, Sanz E, Boschetti E, Righetti PG. Exploring the venom proteome of the estern diamondback rattlesnake, Crotalus atrox, via snake venomics and combinational peptide ligand library approaches. J Proteome Res. 2009:8:3055-67.

7. Costa TR, Burin SM, Menaldo DL, Castro FA, Sampaio SV. Snake venom L-amino acid oxidases: an overview on their antitumor effects. J Venom Anim Toxins incl Trop Dis. 2014;20:23.

8. Al-Quraishy S, Dkhil MA, Moneim AEA. Hepatotoxicity and oxidative stress induced by Naja haje crude venom. J Venom Anim Toxins ind Trop Dis. 2014;20:42.

9. Sunitha K, Hemshekhar M, Thushara RM, Sebastin-Santhosh M, ShanmugaSundaram M, Kemparaju K, Girish KS. Inflammation and oxidative stress in viper bite: An isight within and beyond. Toxicon. 2015;98:87-98. 
10. He W, Xiaole C, Mei Z, Lei W, Tianbao C, Chris S. Molecular characterization of three novel phospholipase A2 proteins from the venom of atheris chlorechis, atheris nitschei and atheris squamigera. Toxins. 2016;8(6):168.

11. Park MH, Jo M, Won D, Song HS, Song MJ, Hong JT. Snake venom toxin from Vipera lebetina turanica sensitizes cancer cells to TRAIL through ROSand JNK-mediated upregulation of death receptors and downregulation of survival proteins. Apoptosis. 2012;17(12):1316-26.

12. Nanda BL, Nataraju A, Rajesh R, Rangappa KS, Shekar MA, Vishwanath BS PLA2 mediated arachidonate free radicals: PLA2 inhibition and neutralization of free radicals by antioxidants-a new role as antiinflammatory molecule. Curr Top Med Chem. 2007;7(8):765-77.

13. Abdurrahman AA, Haseeb AK, Khalaf AM, Rajamohamed AM. Time-course of lipid peroxidation in different organs of mice treated with Echis pyramidum snake venom. J Biochem Mol Toxicol. 2006;20(2):93-5.

14. Barraviera B, Machado PEA, Meira DA, Curi PR, Martins JNP, Souza MJ. Glucose-6-phosphate dehydrogenase and glutathione reductase activity in methemoglobin reduction by methylene blue and cystamine. Study on glucose-6-phosphate dehydrogenase-deficient individuals, on normal subjects and on riboflavin-treated subjects. Rev Inst Med Trop Sao Paulo. 1988;30(5):370-8.

15. Barraviera B. Effect of antimalarial drugs and of clindamycin on erythrocyte metabolism. A review. Rev Inst Med Trop Sao Paulo. 1989;31(3):200-5.

16. Du XY, Clemetson KJ. Snake venom L-amino acid axidases. Toxicon. 2002; 40(6):659-65.

17. Meléndez-Martínez D, Macias-Rodríguez E, Vargas-Caraveo A, MartínezMartínez A, Gatica-Colima A, Plenge-Tellechea LF. Capillary damage in the area postrema by venom of the northern black-tailed rattlesnake (Crotalus molossus molossus). J Venom Res. 2014;5:1-5.

18. Lowry OH, Rosenbrough NJ, Farr AL, Randall RJ. Protein measurement with the Folin Phenol Reagent. J Biol Chem. 1951;193:265-75.

19. Das D, Urs N, Hiremath V, Vishwanath BS, Doley R. Biochemical and biological characterization of Naja kaouthia venom from North-East India and its neutralization by polyvalent antivenom. J Venom Res. 2013;4:31-8.

20. Sambrook J and Russell DW. Molecular cloning, A laboratory manual. 3rd ed. New York: Cold Spring Harbor laboratory Press; 2001.

21. Barraza-Garza G, Castillo-Michel H, de la Rosa LA, Martinez-Martinez A, PerezLeon JA, Cotte M, Alvarez-Parrilla E. Infrared Spectrocospy as a tool to study the antioxidant activity of polyphenolic compounds in isolated rat enterocytes. Oxid Med Cell Longev. 2016;1:1-10.

22. Doley R, Zhou X, Kini M. Snake venom phospholipase A2 enzymes. In: Mackessy SP, editor. Handbook of venoms and toxins of reptiles. Florida: CRC Press; 2010. p. 174-205.

23. Braga MDM, Costa Martins AM, Amora DN, Beserra de Menezes D, Toyama MH, Toyama DO, Marangoni S, Alves CD, Ferreira Barbosa OS, de Sousa Alves R, Fonteles MC, Azul Monteiro HS. Purification and biological effects of L-amino acid oxidase isolated from Bothrops insularis venom. Toxicon. 2008;51:199-207.

24. Lee ML, Chung I, Fung SY, Kanthimathi MS, Tan SH. Antiproliferative activity of king cobra (Ophiophagus hannah) venom L-amino acid oxidase. Basic Clin Pharmacol Toxicol. 2014;114:336-43.

25. Fung SY, Lee ML, Tan NH. Molecular mechanism of cell death induced by king cobra (Ophiophagus hanna) venom L-amino acid oxidase. Toxicon. 2015;96:38-45.

26. Sharma RD, Katkar GD, Sundaram MS, Paul M, NaveenKumar SK, Swethakumar B, Hemshekhar M, Girish KS, Kemparaju K. Oxidative stressinduced methemoglobinemia is the silent killerduring snakebite: a novel and strategic neutralization by melatonin. J Pineal Res. 2015;59:240-54.

27. Ramírez GA, Fletcher Jr PL, Possani DL. Characterization of the venom from Crotalus molossus nigrescens Gloyd (Black tail rattlesnake): Isolation of two proteases. Toxicon. 1990;28(3):285-97.

28. Escalante T, Shannon JD, da Silva AM M, Gutierrez JM, Fox JW. Novel insights into capillary vessel basement membrane damage by snake venom hemorrhagic metalloproteinases: a biochemical and immunocyto-chemical study. Arch Biochem Biophys. 2006;455:144-53.

29. Escalante T, Ortiz N, Rucavado A, Sánchez EF, Richardson M, Fox JW, Gutiérrez JM. Role of Collagens and perlecan in microvascular stability: Exploring the mechanism of capillary vessel damage by snake venom metalloproteinases. PLoS ONE. 2011;6(12):e28017.

30. Benseny-Cases N, Klementieva O, Cotte M, Ferrer I, Cladera J. Microspectroscopy $(\mu \mathrm{FTIR})$ reveals co-localization of lipid oxidation and amyloid plaques in human Alzheimer disease brains. Anal Chem. 2014;86: 12047-54.
31. Vargas-Caraveo A, Castillo-Michel H, Mejia-Carmona G, Pérez-Ishiwara D, Cotte M, Martínez-Martínez A. Preliminary studies of the effects of psychological stress on circulating lymphocytes analyzed by synchrotron radiation based-Fourier transform infrared microspectroscopy. Spectrochim Acta A Mol Biomol Spectrosc. 2014;128:141-6.

32. Al Asmari A, Al Moutaery K, Manthari RA, Khan HA. Time-course of lipid peroxidation in different organs of mice treated with Echis pyramidum snake venom. J Biochem Mol Toxicol. 2006;20:93e95.

\section{Submit your next manuscript to BioMed Central and we will help you at every step:}

- We accept pre-submission inquiries

- Our selector tool helps you to find the most relevant journal

- We provide round the clock customer support

- Convenient online submission

- Thorough peer review

- Inclusion in PubMed and all major indexing services

- Maximum visibility for your research

Submit your manuscript at www.biomedcentral.com/submit
Biomed Central 